2018-12

\title{
On the evaluation of power density models for oscillatory baffled reactors using CFD
}

Jimeno, $\mathrm{G}$

http://hdl.handle.net/10026.1/17100

\begin{abstract}
10.1016/j.cep.2018.11.002
Chemical Engineering and Processing - Process Intensification

Elsevier BV
\end{abstract}

All content in PEARL is protected by copyright law. Author manuscripts are made available in accordance with publisher policies. Please cite only the published version using the details provided on the item record or document. In the absence of an open licence (e.g. Creative Commons), permissions for further reuse of content should be sought from the publisher or author. 


\section{Accepted Manuscript}

Title: On the evaluation of power density models for oscillatory baffled reactors using CFD

Authors: Guillermo Jimeno, Yeaw Chu Lee, Xiong-Wei Ni

PII: $\quad$ S0255-2701(18)30539-7

DOI: $\quad$ https://doi.org/10.1016/j.cep.2018.11.002

Reference: $\quad$ CEP 7417

To appear in: $\quad$ Chemical Engineering and Processing

Received date: $\quad 8$ May 2018

Revised date: $\quad 13$ October 2018

Accepted date: $\quad 2$ November 2018

Please cite this article as: Jimeno G, Lee YC, Ni X-Wei, On the evaluation of power density models for oscillatory baffled reactors using CFD, Chemical Engineering and Processing - Process Intensification (2018), https://doi.org/10.1016/j.cep.2018.11.002

This is a PDF file of an unedited manuscript that has been accepted for publication. As a service to our customers we are providing this early version of the manuscript. The manuscript will undergo copyediting, typesetting, and review of the resulting proof before it is published in its final form. Please note that during the production process errors may be discovered which could affect the content, and all legal disclaimers that apply to the journal pertain. 


\section{On the evaluation of power density models for oscillatory baffled reactors using CFD}

Guillermo Jimeno ${ }^{\mathrm{a}}$, Yeaw Chu Lee ${ }^{\mathrm{b}}$ and Xiong-Wei Ni ${ }^{\mathrm{a} *}$

${ }^{a}$ EPSRC, Centre for Continuous Manufacturing and Crystallisation (CMAC), Centre for

Oscillatory Baffled Reactor Applications (COBRA), School of Engineering and Physical Science, Chemical Engineering, Heriot Watt University, Edinburgh. EH14 4AS, UK

${ }^{\mathrm{b}}$ School of Engineering and Physical Science, Mechanical Engineering, Heriot Watt University, Edinburgh. EH14 4AS, UK

*Corresponding author; email: x.ni@hw.ac.uk; Tel: 00441314513781

Graphical abstract

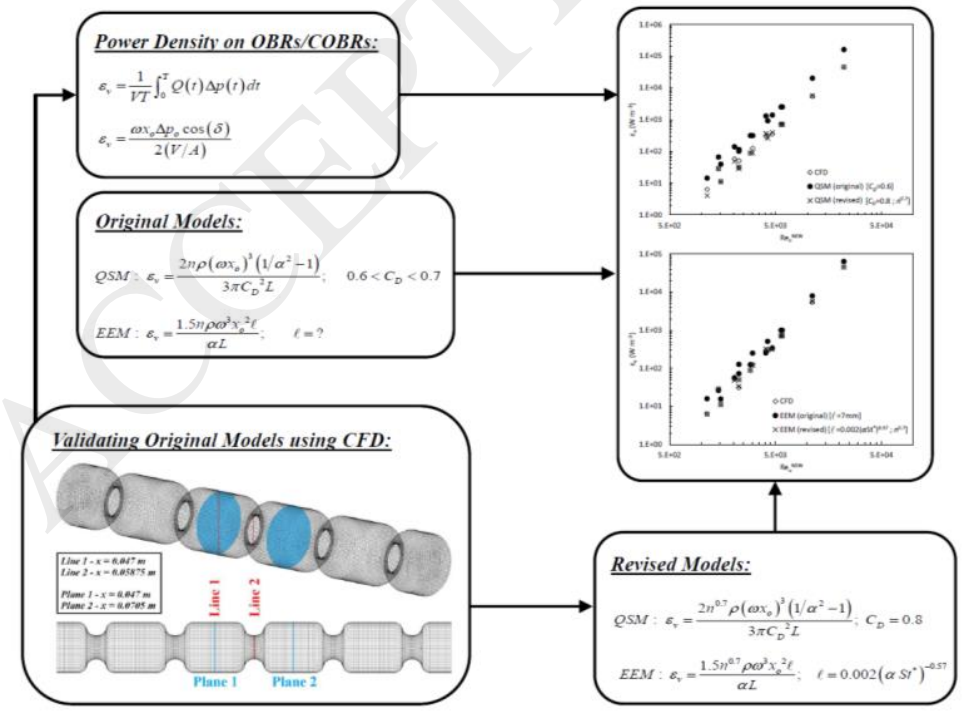




\section{Highlights}

- CFD validation of the two existing models for the estimation of power density in oscillatory baffled devices is for the first time investigated.

- Based on our CFD validation, the best fit would require the revision of the "quasi-steady" model with a power law dependency on the number-of-baffles term and an appropriate orifice discharge coefficient.

- Likewise, the "eddy enhancement" model has been revised and updated with the same power law dependency and an empirical model to appropriately estimate "mixing length", as we have demonstrated that the "mixing length" is not a constant for a given device.

- Both models are validated for a much wider application range than originally stated and for both batch and continuous operations.

- Both revised models can be used interchangeably with high confidence.

\section{ABSTRACT}

While continuous oscillatory baffled reactors (COBR) have been proven a viable alternative to traditional batch reactors for organic synthesis and crystallization, research into the estimation of power density for this type of device has largely been stagnated for the past 25 years. This work reports, for the first time, detailed analysis and examination of the applicability, capability and deficiencies of two existing models using CFD methodology. The "quasi-steady" model (QSM) over-estimates power dissipation rates due to the inaccurate formulation of two of its geometric parameters for modern COBRs. By using a revised power law dependency on the number-of-baffles term $\left(n^{x}\right)$ and an appropriate orifice discharge coefficient $\left(C_{D}\right)$, we demonstrate that the updated QSM can not only be used for a much wider application range than previously outlined, but also for both batch and continuous operations. The "eddy enhancement" model (EEM) generally provides better predictions of power density for the conditions tested; however, its accuracy can substantially be enhanced by applying the aforementioned power law dependency on $n$ and an empirical correlation proposed in this work to estimate EEM's "mixing length". After full validation, both models give very similar power density estimations and can be used interchangeably with high confidence. 
Keywords: power density; oscillatory baffled reactors; pressure drop propagation; computational fluid dynamics (CFD).

\section{Introduction}

While stirred tank reactors have been the workhorse in chemical industry, tubular plug flow reactors, such as continuous oscillatory baffled reactors (COBR), have emerged as a viable alternative. Significant process and economic benefits were reported in the utilization of COBR in a broad range of processes, e.g. crystallization, ${ }^{1-17}$ reactions, ${ }^{18-20}$ heterogeneous catalysis $^{21-23}$ and fermentation processes. ${ }^{24,25}$ However, in terms of evaluation of power dissipation rate for this type of reactors, research has largely been stagnated for the past 25 years. ${ }^{26}$ Essentially two published models have been used in the field of COBR and OBR (oscillatory baffled reactors): the "quasi-steady" model (QSM) from the work of Jealous and Johnson $^{27}$ and the "eddy enhancement" model (EEM) by Baird and Stonestreet. ${ }^{28,29}$ The origin of both models was stemmed from the evaluation of pressure drop over oscillatory devices; while the equations were empirical, research has neither been carried out on the validation of the above models nor on how these models could be used in continuous operation where there is a net flow. In this paper, we report, for the first time, a detailed analysis and examination of the applicability, the capability and the deficiencies of the two models using a CFD methodology.

\section{Background for power dissipation models}

In order to predict power density $\left(\varepsilon_{v}\right)$ due to pulse generation in pulsed columns, Jealous and Johnson in 1955 developed the QSM from pressure drop, which accounted for inertial and frictional effects of the flow, as well as pressure drop due to a static head that was present on 
their experimental setup. ${ }^{27}$ QSM power density equation for oscillatory baffled reactors was then derived from the work of Jealous and Johnson as: ${ }^{28,29}$

$$
\varepsilon_{v}=\frac{2 n \rho\left(\omega x_{o}\right)^{3}\left(1 / \alpha^{2}-1\right)}{3 \pi C_{D}{ }^{2} L}
$$

Due to the constriction of an orifice baffle, it is the frictional losses, instead of inertia, that resulted in the overall gain in kinetic energy. The geometric parameters taking part in eq. (1) include the orifice discharge coefficient $\left(C_{D}\right)$, usually taken as $0.6-0.7,{ }^{27-33}$ the reactor's length $(L)$ in meters, the number of baffles $(n)$ and the ratio of the area of the orifice over the area of the tube, known as the restriction ratio $\left(\alpha=D_{b}^{2} / D^{2}\right), D$ is the diameter of the tube (m) and $D_{b}$ is the diameter of the baffle hole $(\mathrm{m})$; operational parameters involve $\omega=2 \pi f$ as the oscillation angular frequency $\left(\mathrm{rad} \mathrm{s}^{-1}\right), x_{o}$ the oscillation center-to-peak amplitude $(\mathrm{m})$ and $f$ the oscillation frequency $(\mathrm{Hz})$; physical parameter is the fluid density $(\rho)\left(\mathrm{kg} \mathrm{m}^{-3}\right)$. We note that a term counting for the net flow velocity was not included in eq. (1), as pulse columns have been operated batch-wise.

It is generally thought that QSM works well for low frequencies (below $5 \mathrm{~Hz}$ ) and high amplitudes (above $5 \mathrm{~mm}$ ). ${ }^{27,28,34}$ However, this is not in full agreement with the work of Panton and Goldman, who, after investigating the derivations of QSM, reported that QSM was not strictly valid when $\left(3<\left(\omega x_{o}\right) /(v \omega)^{1 / 2}<100\right)$ where $v$ is the kinematic viscosity $\left(\mathrm{m}^{2}\right.$ $\left.\mathrm{s}^{-1}\right) ;{ }^{35}$ note that all the conditions presented in this study are within the aforementioned range. In addition, selection of the $C_{D}$ value in the QSM also affects the accuracy of the model. Furthermore, the assumption made by Jealous and Johnson that there is a linear relationship between the number of baffles in the device and the frictional pressure losses due to their 
orifice constriction is yet to be proven for OBRs/COBRs. This argument is further examined, developed and addressed in section 5.2 of this paper.

Braid and Stonestreet developed an empirical EEM model to predict overall power dissipation rates, coupling acoustic behavior with local eddy turbulence, ${ }^{28}$ based on the prediction of frictional pressure drop as the acoustic resistance of a single orifice plate:

$\varepsilon_{v}=\frac{1.5 n \rho \omega^{3} x_{o}^{2} \ell}{\alpha L}$

While similar geometric, physical and operational parameters are involved in this model, "mixing length" $\ell(\mathrm{m})$ is an additional parameter and has a value similar to a characteristic length scale of the reactor, e.g. a value of $7 \mathrm{~mm}$ was selected in previous research with a tube diameter of $12 \mathrm{~mm} .{ }^{28}$ This model was proposed for higher frequencies (above $5 \mathrm{~Hz}$ ) and lower amplitudes (below $5 \mathrm{~mm}$ ), hence filling the gap left by the QSM. However, the dependence of power dissipation rate on mixing length casts doubts, as mixing length is often unknown and has not accurately been predicted in OBR. Furthermore, it was unclear whether this model is suitable for continuous operation. The EEM, similarly to the QSM, also assumes a linear relationship between the number of baffles and frictional pressure losses.

Accompanying the EEM, the phase shift between velocity and pressure waves was given as: $^{28}$

$$
\delta=\tan ^{-1}\left(\frac{L K_{i}}{3 n \ell}\right)
$$


where $K_{i}$ is a geometry-dependent inertial corrector factor (a value of 0.9 was selected by Braid and Stonestreet in their work). Although the two empirical models mentioned above, QSM in particular, have commonly been used by researchers in order to compare performances of oscillatory baffled reactors with other types of devices, no validation has yet been conducted.

\section{Validation approach}

The targeted device is a NiTech DN15 COBR reactor (DN15 for short) with the design details provided by the manufacturer, Alconbury Weston Ltd (http://www.a-w-l.co.uk/); Figure 1 shows the geometric dimensions of the DN15, the overall length is $752 \mathrm{~mm}$ containing 32 baffled cells.

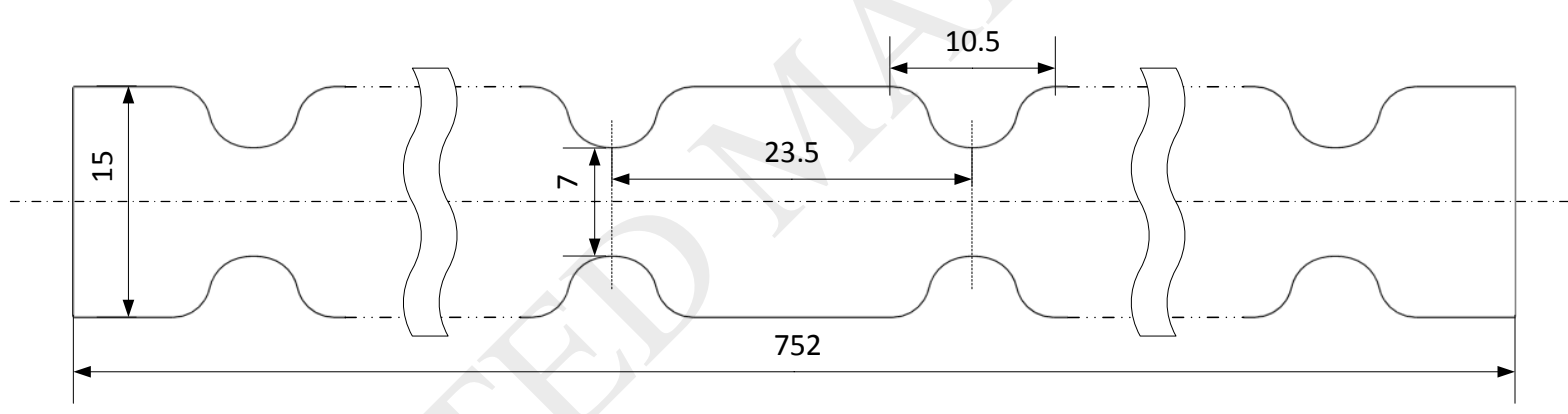

Figure 1. Dimensions of the NiTech DN15 straight section used in CFD simulations; all quotes are in $\mathrm{mm}$

Table 1 lists the conditions for our parametric CFD study covering a wide range of both geometric and operational parameters such as baffle hole diameter $\left(D_{b}\right)$, baffle spacing $\left(L_{b}\right)$, volumetric flow rate $(Q)$, oscillation frequency $(f)$ and center-to-peak amplitude $\left(x_{o}\right)$. The net flow Reynolds numbers $\left(\operatorname{Re}_{\mathrm{n}}=u_{n e t} \rho D / \mu\right)$ and oscillatory Reynolds numbers $\left(\operatorname{Re}_{o}=\omega x_{\circ} \rho D / \mu\right)$ are given in the last two columns of Table 1. 
Table 1. Parametric study list of conditions simulated

\begin{tabular}{cccccccc}
\hline Run \# & $Q(\mathrm{ml} / \mathrm{min})$ & $f(\mathrm{~Hz})$ & $x_{o}(\mathrm{~mm})$ & $D_{b}(\mathrm{~mm})$ & $L_{b}(\mathrm{~mm})$ & $\mathrm{Re}_{\mathrm{n}}$ & $\mathrm{Re}_{\mathrm{o}}$ \\
\hline 1 & 50 & 0.5 & 14 & 7 & 23.5 & 70.5 & 657 \\
2 & 50 & 1 & 14 & 7 & 23.5 & 70.5 & 1313 \\
3 & 50 & 2 & 14 & 7 & 23.5 & 70.5 & 2626 \\
4 & 50 & 4 & 14 & 7 & 23.5 & 70.5 & 5253 \\
5 & 50 & 8 & 14 & 7 & 23.5 & 70.5 & 10505 \\
6 & 50 & 1 & 5 & 7 & 23.5 & 70.5 & 469 \\
7 & 50 & 1 & 23 & 7 & 23.5 & 70.5 & 2157 \\
8 & 50 & 1 & 14 & 5 & 23.5 & 70.5 & 1313 \\
9 & 50 & 1 & 14 & 9 & 23.5 & 70.5 & 1313 \\
10 & 50 & 1 & 14 & 7 & 47 & 70.5 & 1313 \\
11 & 50 & 1 & 14 & 7 & 94 & 70.5 & 1313 \\
12 & 100 & 2 & 5 & 7 & 23.5 & 141 & 938 \\
13 & 100 & 2 & 7 & 7 & 23.5 & 141 & 1313 \\
14 & 100 & 2 & 10 & 7 & 23.5 & 141 & 1876 \\
15 & 100 & 2 & 14 & 7 & 23.5 & 141 & 2626 \\
\hline
\end{tabular}

In oscillatory flow devices, both inlet velocity and pressure drop follow sinusoidal wave forms, separated by a phase shift $(\delta)$, as represented in Figure 2. The time-averaged power density, referred to as power density $\left(\varepsilon_{v}\right)$ from this point onwards, in a COBR can be calculated by solving:

$\varepsilon_{v}=\frac{1}{V T} \int_{0}^{T} Q(t) \Delta p(t) d t$

where $V$ is the volume of the system $\left(\mathrm{m}^{3}\right), T$ the oscillation period (s), $Q(t)$ the volumetric flow rate $\left(\mathrm{m}^{3} \mathrm{~min}^{-1}\right)$ defined as $Q(t)=A \cdot u(t), A$ being the cross-sectional area $\left(\mathrm{m}^{2}\right)$, the velocity profile $u(t)=u_{n e t}+\omega x_{o} \sin (\omega t)$ and $u_{n e t}$ is the inlet net velocity $\left(\mathrm{m} \mathrm{s}^{-1}\right)$. The temporal pressure drop profile across the device $\Delta p(t)(\mathrm{Pa})$ has often been assumed to have a sinusoidal wave form similar to that of the flow motion, defined as 
$\Delta p(t)=\Delta p_{n e t}+\Delta p_{o} \sin (\omega t+\delta),{ }^{28,29,36}$ where $\Delta p_{o}$ is the maximum center-to-peak pressure drop fluctuation, $\Delta p_{n e t}$ the net pressure drop and $\delta$ the phase shift. Making use of this hypothesis, the integration of eq. (4) over an oscillatory cycle results in:

$$
\varepsilon_{v}=\frac{\omega x_{o} \Delta p_{o} \cos (\delta)+2 u_{n e t} \Delta p_{n e t}}{2(V / A)} \approx \frac{\omega x_{o} \Delta p_{o} \cos (\delta)}{2(V / A)}
$$

The volume to cross-sectional area ratio in eq. (5) is often substituted by the reactor's length $(L)$; however, while this is true for sharp-edged disk-like baffles, it is far from reality for smooth-edge baffles as observed in Figure 1, e.g. the percentage difference between VIA and $L$ is $25 \%$ for all runs, except for runs \#8 - 11 where this difference ranges from 5 to $30 \%$. For this reason, V/A was used in equations (1), (2) and (5) as opposed to $L$ throughout this study.

Our validation work starts by generating data of pressure drop $\Delta p(t)$ over a fixed length (752 mm) of the DN15 using CFD for 10 cycles of oscillation. In order to minimize the effect of boundary conditions, the first and the last two baffle cells were discarded. The areaweighted average static pressure was monitored for two cross-sectional planes placed at 47 $\mathrm{mm}$ from the inlet, marked as Plane $1\left(p_{1}\right)$, and $47 \mathrm{~mm}$ from the outlet as Plane $2\left(p_{2}\right)$, from which pressure drop profiles were obtained using $\Delta p(t)=p_{1}(t)-p_{2}(t)$ over the remaining 28 baffled cells $(0.658 \mathrm{~m})$. For each run, the simulated time-dependent pressure drop profile, $\Delta p(t)$, was extracted and utilized in the numerical integration of eq. (4) for the calculation of power density. The simulated power density of a particular condition is then compared with the estimated power densities from the QSM and the EEM, which are directly calculated using eq. (1) and eq. (2) respectively, where a mixing length of $7 \mathrm{~mm}$ is used in EEM as proposed by previous work. ${ }^{28}$ In this way, the simulated power density values are compared 
to those provided by QSM and EEM, enabling a detailed examination and validation of these two models for a wide range of geometric and operational conditions.

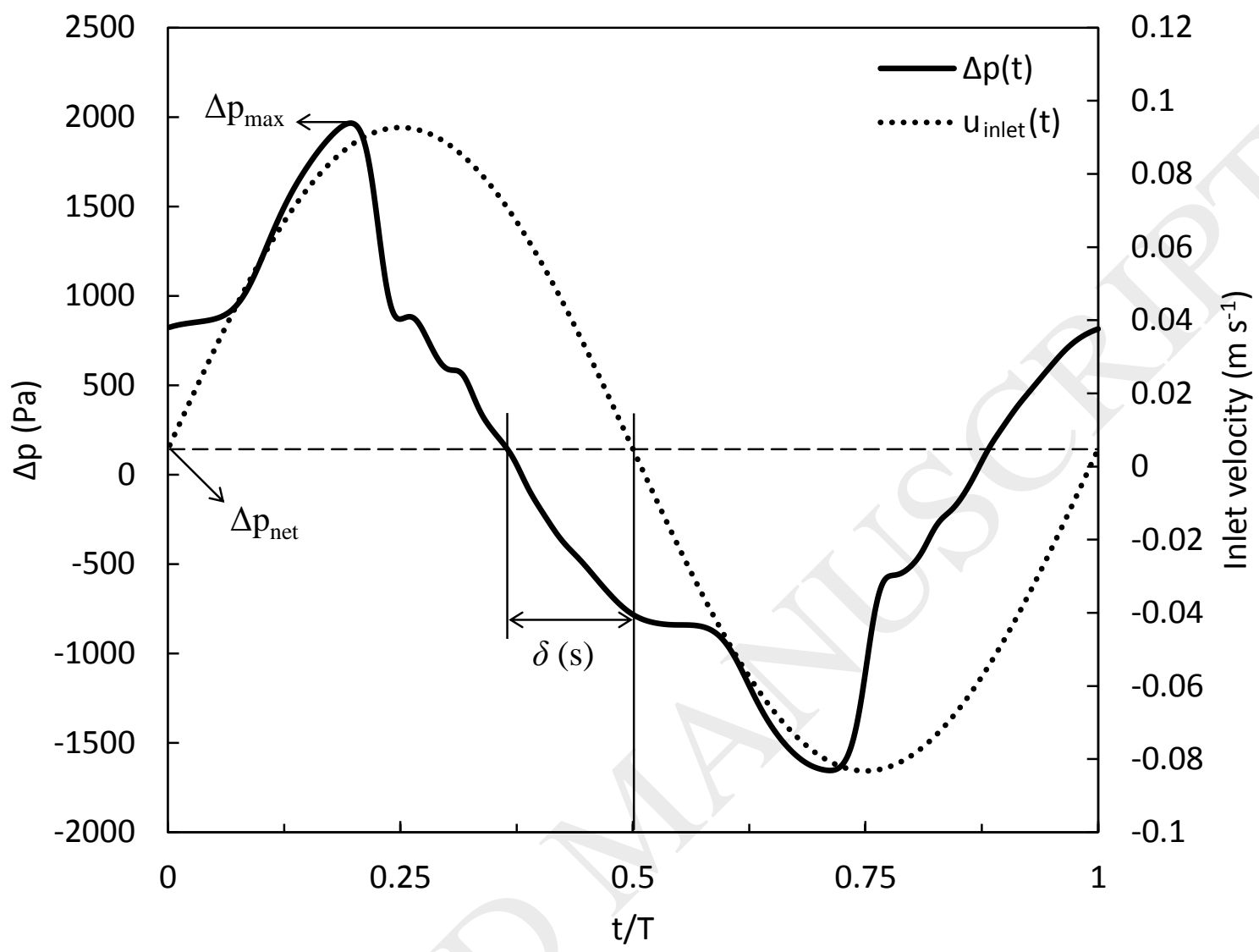

Figure 2. Inlet velocity and pressure drop wave forms illustrating phase angle; cycleaveraged simulated data from run \#2

The averaged absolute error (AAE) (\%) between the simulated and model predicted power densities was quantified as:

$A A E(\%)=\frac{\sum_{i=1}^{n}\left(\frac{\left|\phi_{i}^{\text {predicted }}-\phi_{i}^{\text {simulated }}\right|}{\phi_{i}^{\text {simulated }}} \times 100\right)}{n}$ 
where $i$ is a single case/run, $n$ the total number of cases in this study and $\phi$ the property under evaluation $\left(\varepsilon_{v}\right)$.

\section{Computational simulations set-up}

\subsection{Mesh}

Table 2 shows the mesh characteristics used for the simulations.

Table 2. Mesh characteristics of the DN15 used in CFD simulations except runs \#8-11

\begin{tabular}{lr}
\hline Baffle cells in reactor (\#) & 32 \\
Computational nodes per baffle cell (\#) & $\sim 117 \mathrm{k}$ \\
\hline
\end{tabular}

\subsection{Numerical model}

The ANSYS® Fluent 16.0 CFD package was used for all the numerical simulations of this work. Three-dimensional incompressible time-dependent Navier-Stokes equations were solved:

$\nabla \cdot \vec{u}=0$

$\rho\left(\frac{\partial \vec{u}}{\partial t}+\vec{u} \nabla \cdot \vec{u}\right)=-\nabla p+\mu \nabla^{2} \vec{u}$

All the simulations were performed using the pressure-based segregated solver together with the SIMPLE pressure-velocity coupling algorithm. A second order upwind scheme was utilized for the spatial discretization of the momentum equation; a second order scheme for 
the interpolation of pressure at the faces of the grid and a first order implicit scheme for the time discretization.

The time-step was set to $2 \mathrm{~ms}$ throughout all simulations, except for run \#5 $(f=8 \mathrm{~Hz})$ where a time-step of $0.5 \mathrm{~ms}$ was selected. This ensured that the convergence criteria (residuals of $10^{-3}$ and $10^{-4}$ for continuity and momentum equations respectively) were met and the number of time-steps per oscillation cycle was above 125 , which is higher than others reported in recent literature for these types of oscillatory baffled devices. ${ }^{37,38}$ The average value of the Courant-Friedrichs-Lewy (CFL) coefficient was consistently maintained below 6 and the maximum CLF value below 50.

In order to minimize the impact of inlet boundary conditions on the main flow, the inlet oscillatory velocity was imposed with a fully developed parabolic profile, $u_{\text {inlet }}(r, t)=2 \cdot u(t) \cdot\left(1-\frac{r^{2}}{R^{2}}\right)$, where $u(t)=u_{n e t}+\omega x_{o} \sin (\omega t)$. The outlet boundary conditions were set at constant gauge pressure of $0 \mathrm{~Pa}$. Incompressible water $\left(\rho=998.2 \mathrm{~kg} \mathrm{~m}^{-3}, \mu=\right.$ $1.003 \cdot 10^{-3} \mathrm{~kg} \mathrm{~m}^{-1} \mathrm{~s}^{-1}$ ) was the selected fluid for this study.

All simulations were performed using a laminar solver; this is consistent with literature, as this solver has extensively been used during the past ${ }^{39-41}$ and present decade $\mathrm{e}^{37,38,42-44}$ when modelling fluid flow through oscillatory baffled reactors using CFD, including flows at relatively high $\operatorname{Re}_{o}$ (up to 8043). ${ }^{45,46}$

\subsection{Mesh sensitivity test}

The number of computational nodes per baffle was selected through a mesh sensitivity analysis undertaken on a 5-baffle-cell tube geometry, illustrated in Figure 3, considering 
global mesh refinement. This analysis was performed at the same operating conditions of run \#5 (Table 1), as it presents the most adverse conditions of this study, proving the highest axial velocities $($ Reo $=10505)$ and the most rapid changes of flow direction $(f=8 \mathrm{~Hz})$, hence requiring a finer mesh. Simulations were run for 24 oscillatory cycles. Pressure drop vs time profiles, $\Delta p(t)=p_{1}(t)-p_{2}(t)$, and velocity magnitude vs time profiles extracted at lines $1 \& 2$ and planes $1 \& 2$ (as shown in Figure 3), were cycle-averaged. The resulting pressure drop and velocity profiles (duration of an oscillatory cycle) were compared for meshes of five different resolutions, using the coefficient of determination $\left(\mathrm{R}^{2}\right)$ :

$$
R^{2}=1-\frac{S S_{r e s}}{S S_{t o t}}=1-\frac{\sum_{i=1}^{n}\left(\phi_{j, i}-\phi_{1, i}\right)^{2}}{\sum_{i=1}^{n}\left(\phi_{1, i}-\overline{\phi_{1, i}}\right)^{2}}
$$

where $S S_{\text {tot }}$ is the total sum of squares of the target profile (that from mesh \#1) and $S S_{\text {res }}$ is the sum of squares of residuals between the profile under evaluation (from mesh $\# j$ ) and the target profile, the subscripts $i$ and $n$ represent, respectively, a single data point and the total number of data points of a certain profile, $j$ is the index of a certain mesh and $\phi$ the property under evaluation. 


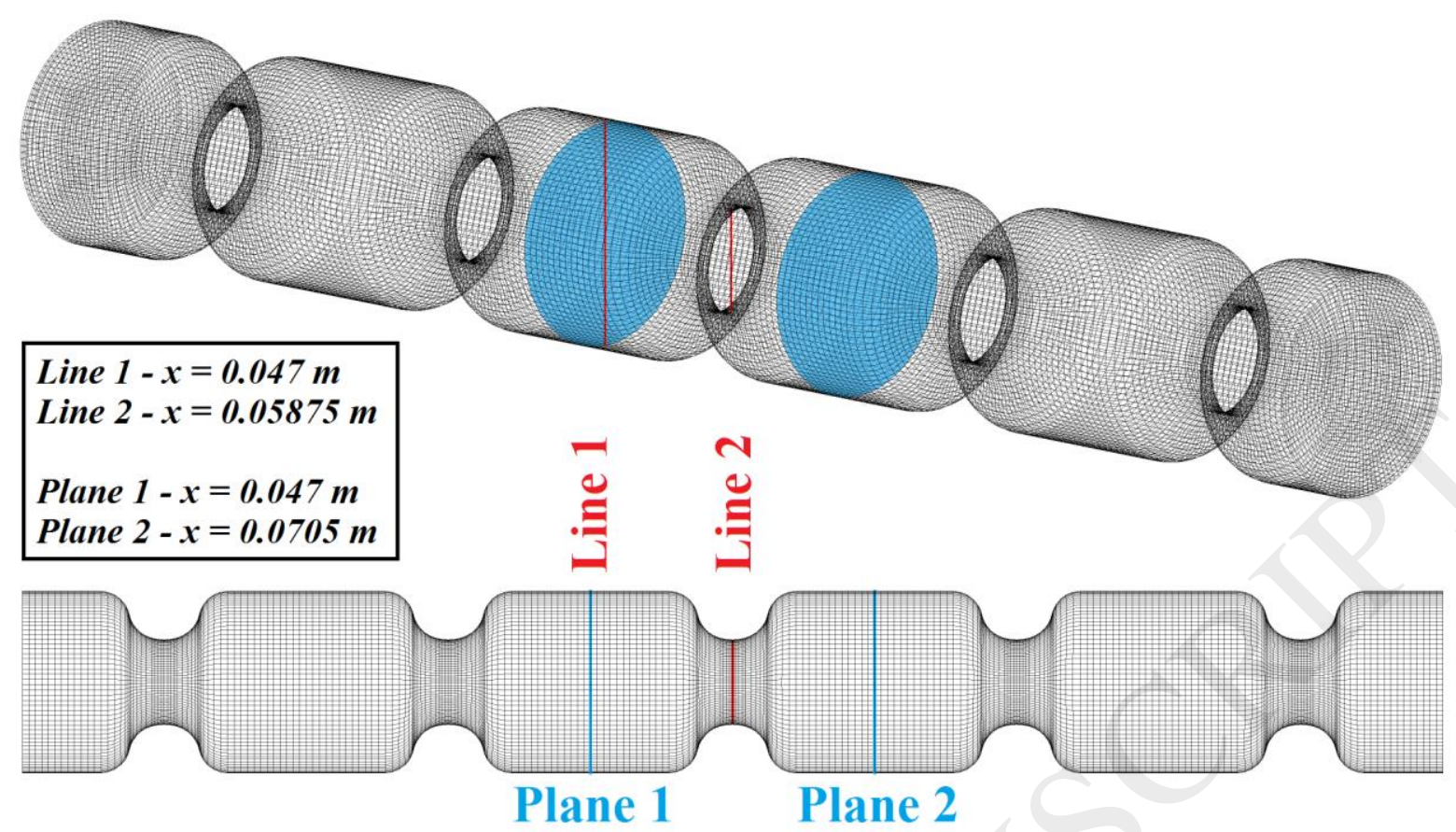

Figure 3. Five-baffle-cells geometry, lines and planes where variables were monitored during mesh independency test

The results from each subsequent mesh were compared to those from mesh \#1. Table 3 summarizes the results of the mesh independency analysis; mesh \#2 was chosen for this study on the balance of accuracy and efficiency, and its density is above the norm reported in literature. ${ }^{39,41,43,45-48}$ All meshes were O-grid structured containing only hexahedral elements and were created on ANSYS ICEM.

Table 3. Mesh sensitivity analysis results $\left(Q=50 \mathrm{ml} / \mathrm{min}, f=8 \mathrm{~Hz}, x_{o}=14 \mathrm{~mm}\right)$

\begin{tabular}{ccccccc} 
& & & \multicolumn{4}{c}{ Velocity Magnitude at } \\
\cline { 3 - 7 } Mesh & \# Nodes $^{*}$ & $\Delta p^{* *}$ & Line 1 & Line 2 & Plane 1 & Plane 2 \\
\hline 1 & $236 \mathrm{k}$ & - & - & - & - & - \\
$\mathbf{2}$ & $\mathbf{1 1 7 ~ k}$ & $\mathbf{0 . 9 7 8}$ & $\mathbf{0 . 9 9 0}$ & $\mathbf{0 . 9 9 7}$ & $\mathbf{0 . 9 9 5}$ & $\mathbf{1 . 0 0 0}$ \\
3 & $64 \mathrm{k}$ & 0.940 & 0.984 & 0.996 & 0.984 & 0.999 \\
4 & $31 \mathrm{k}$ & 0.922 & 0.984 & 0.996 & 0.980 & 0.999 \\
5 & $7 \mathrm{k}$ & 0.670 & 0.911 & 0.989 & 0.825 & 0.997 \\
\hline
\end{tabular}

${ }^{*}$ Number of nodes per baffle cell. 
${ }^{* *}$ Pressure drop profile between planes 1 and $2: \Delta p(t)=p_{1}(t)-p_{2}(t)$.

\section{Results}

In previous CFD simulations of $\mathrm{OBR}$ and $\mathrm{COBR},{ }^{49}$ a quasi-steady state, indicating the flow was fully developed and cycle-repeatable, was achieved in 5-7 cycles of oscillation. Applying the same methodology, Figure 4 (left) shows the change of the volume-weighted averaged strain rate with time; a quasi-steady state is seen after cycle 5. Being conservative, all the data presented on this study were taken from the cycle 7 (included) onwards. Furthermore, Figure 4 (right) plots $\Delta p(t)$ at different oscillatory cycles, visually confirming the repeatability of the results after cycle 7 .
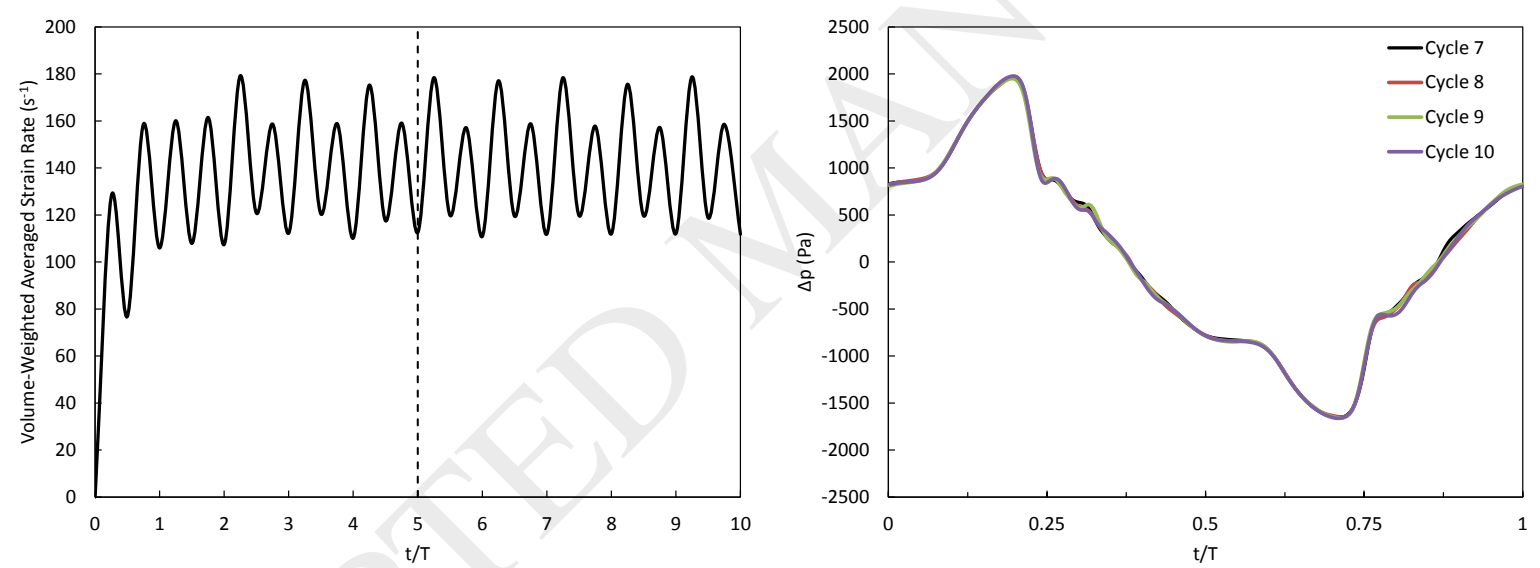

Figure 4. Convergence of strain rate with time (left) and pressure drop wave forms for cycles 7 to 10 (right) $\left(Q=50 \mathrm{ml} / \mathrm{min}, f=1 \mathrm{~Hz}, x_{o}=14 \mathrm{~mm}\right)$

Mazubert et al. predicted $\Delta p_{o}$ and $\varepsilon_{v}$ for different types of baffle configurations using CFD simulations, ${ }^{42}$ their results were the basis for comparison with ours. For a single orifice plate, $D=15 \mathrm{~mm}, D_{b}=8 \mathrm{~mm}, L_{b}=26 \mathrm{~mm}, f=1.05 \mathrm{~Hz}, x_{o}=16.5 \mathrm{~mm}, u_{n e t}=14.05 \mathrm{~mm} \mathrm{~s}^{-1}$, they reported a maximum center-to-peak pressure drop fluctuation per length and a power density 
of $0.73 \mathrm{kPa} \mathrm{m}^{-1}$ and $23.8 \mathrm{~W} \mathrm{~m}^{-3}$ respectively. The baffles utilized by Mazubert et al. were sharp-edged with a width $\left(W_{b}\right)$ of $2 \mathrm{~mm}$, in the axial direction, as opposed to the $10.5 \mathrm{~mm}$ of the smooth-edged baffles used in the present work (Figure 1). While a direct comparison is not possible due to different geometric and operational parameters, since $\Delta p_{o}$ and $\varepsilon_{v}$ are proportional to $\theta$, where $\theta=\left(x_{o} W_{b}\right) /\left(\alpha L_{b}\right)$, the maximum center-to-peak pressure drop fluctuation per length and the power density reported by Mazubert et al. can be compared with those obtained in \#2 of our work $\left(2.3 \mathrm{kPa} \mathrm{m}^{-1}\right.$ and $\left.88.1 \mathrm{~W} \mathrm{~m}^{-3}\right)$ by multiplying Mazubert's data by a ratio of $\theta^{\text {Ours }} / \theta^{\text {Mazubert }}$. In doing so, the data of Mazubert et al. become $2.5 \mathrm{kPa} \mathrm{m}^{-1}$ and $81.8 \mathrm{~W} \mathrm{~m}^{-3}$ respectively, which are very similar to our results obtained from run \#2. Note that to compensate for the shape difference in baffles, i.e. smooth vs sharp edges, $W_{b}=5.6 \mathrm{~mm}$ was used in the calculation of $\theta^{\text {Ours }}$; this is the baffle width a sharp-edged baffle $\left(D_{b}=7 \mathrm{~mm}\right)$ should have in order for the area under its curve to be equal to that of the smooth-edged baffle of the DN15 used in this investigation.

Mackley et al. plotted power density over a section of OBR against $\omega x_{o} D\left(\mathrm{~m}^{2} \mathrm{~s}^{-1}\right)$, showing a third order power law dependency. ${ }^{36}$ For the sake of comparison, the same plot was displayed using our simulated data (Figure 5 left) and a similar third order power law trend was observed here. However, $\omega x_{o} D$ is not a dimensionless group; it has neither physical meaning nor importance, as it does not include all design and operational parameters. When plotting power density against $\omega x_{o} D$ or the widely used oscillatory Reynolds number, see Figure 5 (right), multiple power density values (provided at different operation conditions) are obtained at the same $\omega x_{o} D$ and $\mathrm{Re}_{\mathrm{o}}$. There is generally a knowledge gap in the governing dimensionless groups in this area, because none of the existing dimensionless groups capture all key design and operational parameters, e.g., the oscillatory Reynolds number was directly derived by replacing the net flow velocity with the oscillatory velocity; the Strouhal number 
$\left(\mathrm{St}=D / 4 \pi x_{o}\right)$ only describes a ratio of tube diameter to oscillation amplitude. A revised oscillatory Reynolds number was proposed ${ }^{50}$ as $R e_{o}^{*}=R e_{o} / \sqrt{\alpha}$, accounting for the effect of the baffle diameter, since the smaller the $D_{b}$, the higher the inertia forces of the fluid. This was a step forward, it however did not include the effects of baffle spacing and the net flow of the system; baffle spacing controls the connectivity of eddies and net flow is an essential part of plug flow. In order to capture the effects of all key design and operational parameters, a new dimensionless number is proposed in this study as:

$$
R e_{o}^{N E W}=\frac{u_{T} \rho D}{\mu} \sqrt{\frac{\beta}{\alpha}}
$$

where $u_{T}$ is the total inlet velocity of the system covering both the net and oscillatory flows $\left(u_{T}=\omega x_{o}+u_{n e t}\right)\left(\mathrm{m} \mathrm{s}^{-1}\right)$ and $\beta$ is defined as the ratio of the optimal to user's baffle spacing as $\beta=L_{b}{ }^{o p t} / L_{b}$, and $L_{b}{ }^{o p t}=1.5 D$. The optimal $L_{b} / D$ ratio was identified as 1.5 by visually analyzing flow patterns, ${ }^{51}$ and as 1.8 by quantitatively assessing the gas-liquid mass transfer coefficient in an OBR. ${ }^{30}$ Since 1.5 has most commonly been reported in literature $;^{2,20,22,26,32,40,44,46,52-54}$ it was selected as reference in $\operatorname{Re}_{o}{ }^{\mathrm{NEW}}$. When $\beta$ is greater than one, more baffles than the optimal would be present, increasing the inertia forces of the fluid and vice versa. In this work $\beta$ is 0.96 for all cases, except for runs 12 and 13 . This new index (10) is used throughout the validation work. 

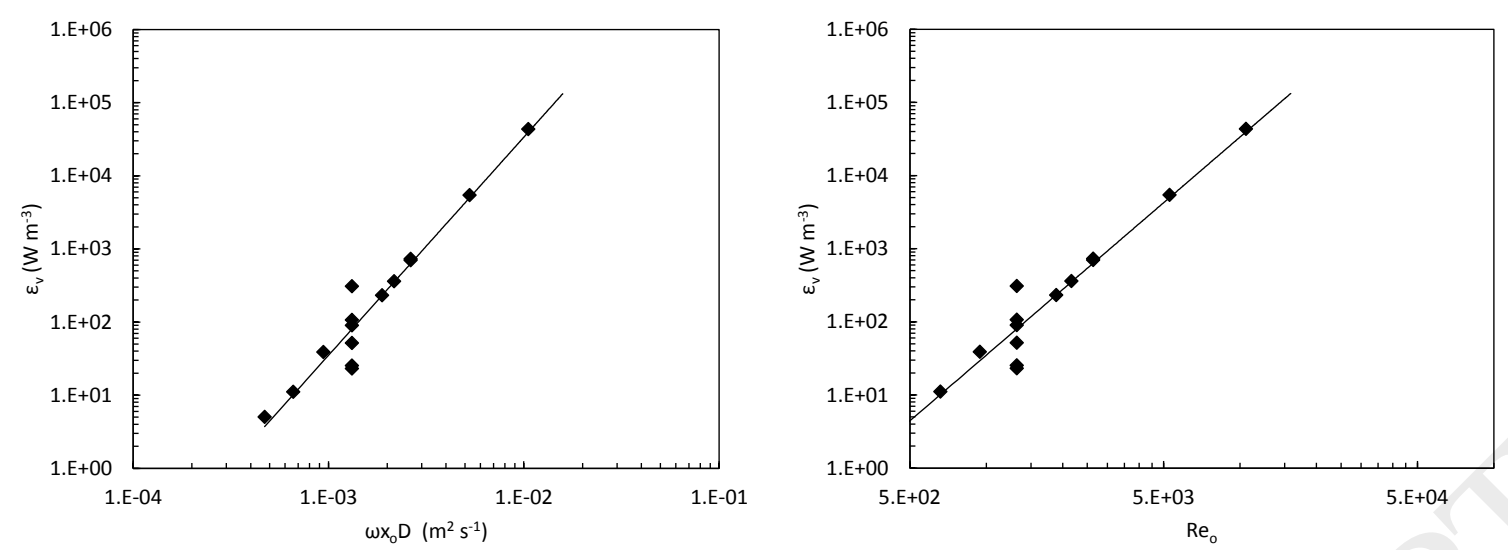

Figure 5. Power density plotted as a function of $\omega x_{o} D$ (left) and Re (right) for runs \#1 to 15

\subsection{Power dissipation rates $\left(\varepsilon_{v}\right)$}

In order to assess the validity of equation (5), where $\Delta p(t)$ is assumed sinusoidal, values of $\Delta p_{n e t}, \Delta p_{o}$ and $\delta$ were obtained from the simulated $\Delta p(t)$ as:

- $\Delta p_{\text {net }}$ is calculated as the time-averaged value of the simulated pressure drop $\Delta p_{n e t}=\overline{\Delta p(t)}$

- Phase shift is calculated by monitoring the times at which $\Delta p(t)$ crosses its $\Delta p_{\text {net }}$ value, e.g. every $T / 2$ seconds, where $T$ is the period of the oscillation. These times are then subtracted from the times at which velocity's sinusoidal wave crosses its $u_{\text {net }}$ value. The resultant values are averaged among cycles 7 to 10 and converted from seconds into radians: $\delta(\mathrm{rad})=(2 \pi / T) \delta(\mathrm{s})=\omega \delta(\mathrm{s})$

- The maximum center-to-peak pressure drop fluctuation, $\Delta p_{o}$, can be obtained by equating the first part of eq. (5), which includes the contributions from the net flow $\left(\Delta p_{n e t}\right.$ and $\left.u_{n e t}\right)$, to the power density obtained from the numerical integration of eq. 
(4) and by solving it for $\Delta p_{o}$, we will call this value $\Delta p_{o}{ }^{\prime}$. However, it can also be calculated by obtaining the maximum value of the cycle-averaged $\Delta p(t)$ profile and then computing $\Delta p_{o}=\Delta p_{\max }-\Delta p_{n e t}$, we will call this value $\Delta p_{o}{ }^{\prime \prime}$.

Table 4 gathers all the information extracted from the simulated data for all the runs performed in this study. Although both the overall pressure drop and overall velocity in the DN15 contain a term counting for net flow, simulated results showed that the contributions of the net flow ( $\Delta p_{n e t}$ and $\left.u_{n e t}\right)$ to power density were negligible in all conditions tested. This was assessed by calculating power density using eq. (4) and the simplified version of eq. (5) (right-hand side) for each simulated condition listed in Table 1, making use of the known variables $u_{n e t}, \omega$ and $x_{o}$, as well as $\Delta p_{n e t}, \Delta p_{o}{ }^{\prime}$ and $\delta$ extracted from the simulated $\Delta p(t)$ profile. The relative percentage differences between the results provided by both equations were then computed, all of which were below 3.6\%. However, it should be noted that the accuracy of eq. (5) is heavily dependent on the appropriate estimation of $\Delta p_{o}$. Table 4 shows how different $\Delta p_{o}{ }^{\prime}$ and $\Delta p_{o}{ }^{\prime \prime}$ could be, reporting relative percentage differences as big as $37 \%$. Figure 6 plots the cycle-averaged pressure drop profile for run \#2, along with the hypothetical sinusoidal profile that $\Delta p(t)$ would display if $\Delta p_{o}=\Delta p_{o}{ }^{\prime}$ and if $\Delta p_{o}=\Delta p_{o}{ }^{\prime \prime}$. The latter presents a much larger area under its curve; it in turn reports a larger power density than the actual non-perfectly-sinusoidal profile. Note that it is advisable to act with caution when making use of eq. (5), as the estimation of $\Delta p_{o}$ could lead to erroneous results if the temporal evolution of $\Delta p(t)$ is unknown.

Table 4. Summary of results extracted from CFD simulations

\begin{tabular}{ccccccc}
\hline Run \# & $\Delta p_{\text {net }}(\mathrm{Pa})$ & $\Delta p_{o}{ }^{\prime}(\mathrm{Pa})$ & $\Delta p_{o}{ }^{\prime \prime}(\mathrm{Pa})$ & $\delta(\mathrm{rad})$ & $\varepsilon_{v}\left(\mathrm{~W} \mathrm{~m}^{-3}\right)^{\text {eq. }(4)}$ & ${ }^{\dagger} \varepsilon_{v}\left(\mathrm{~W} \mathrm{~m}^{-3}\right)^{\text {eq. (5) }}$ \\
\hline 1 & 35.3 & 395.4 & 502.6 & 0.85 & 11.2 & 10.9 \\
\hline
\end{tabular}




\begin{tabular}{ccccccc}
\hline 2 & 58.6 & 1490.1 & 1907.7 & 0.79 & 88.1 & 87.6 \\
3 & 120.0 & 5997.1 & 7409.0 & 0.79 & 709.0 & 708.0 \\
4 & 215.9 & 22632.8 & 28169.3 & 0.77 & 5439.5 & 5437.5 \\
5 & 458.0 & 83695.5 & 99453.0 & 0.62 & 45503.7 & 45499.6 \\
6 & 15.1 & 352.7 & 356.6 & 0.94 & 6.4 & 6.2 \\
7 & 111.6 & 3189.0 & 4071.8 & 0.64 & 353.1 & 352.1 \\
8 & 232.5 & 3923.9 & 5365.2 & 0.54 & 293.8 & 291.6 \\
9 & 28.3 & 710.2 & 642.1 & 1.00 & 30.9 & 30.6 \\
10 & 54.8 & 1021.5 & 1020.4 & 0.72 & 57.7 & 57.2 \\
11 & 27.9 & 638.2 & 600.2 & 0.89 & 28.6 & 28.4 \\
12 & 100.0 & 1329.5 & 1328.1 & 0.91 & 50.4 & 48.6 \\
13 & 171.1 & 2100.8 & 2292.0 & 0.80 & 125.0 & 121.9 \\
14 & 245.4 & 4415.3 & 4185.6 & 0.95 & 309.9 & 305.5 \\
15 & 248.2 & 5907.2 & 7578.9 & 0.77 & 714.9 & 710.4 \\
\hline
\end{tabular}

${ }^{\prime}$ Calculated with the simplified version of eq. (5) (right-hand side) and $\Delta p_{o}=\Delta p_{o}{ }^{\prime}$

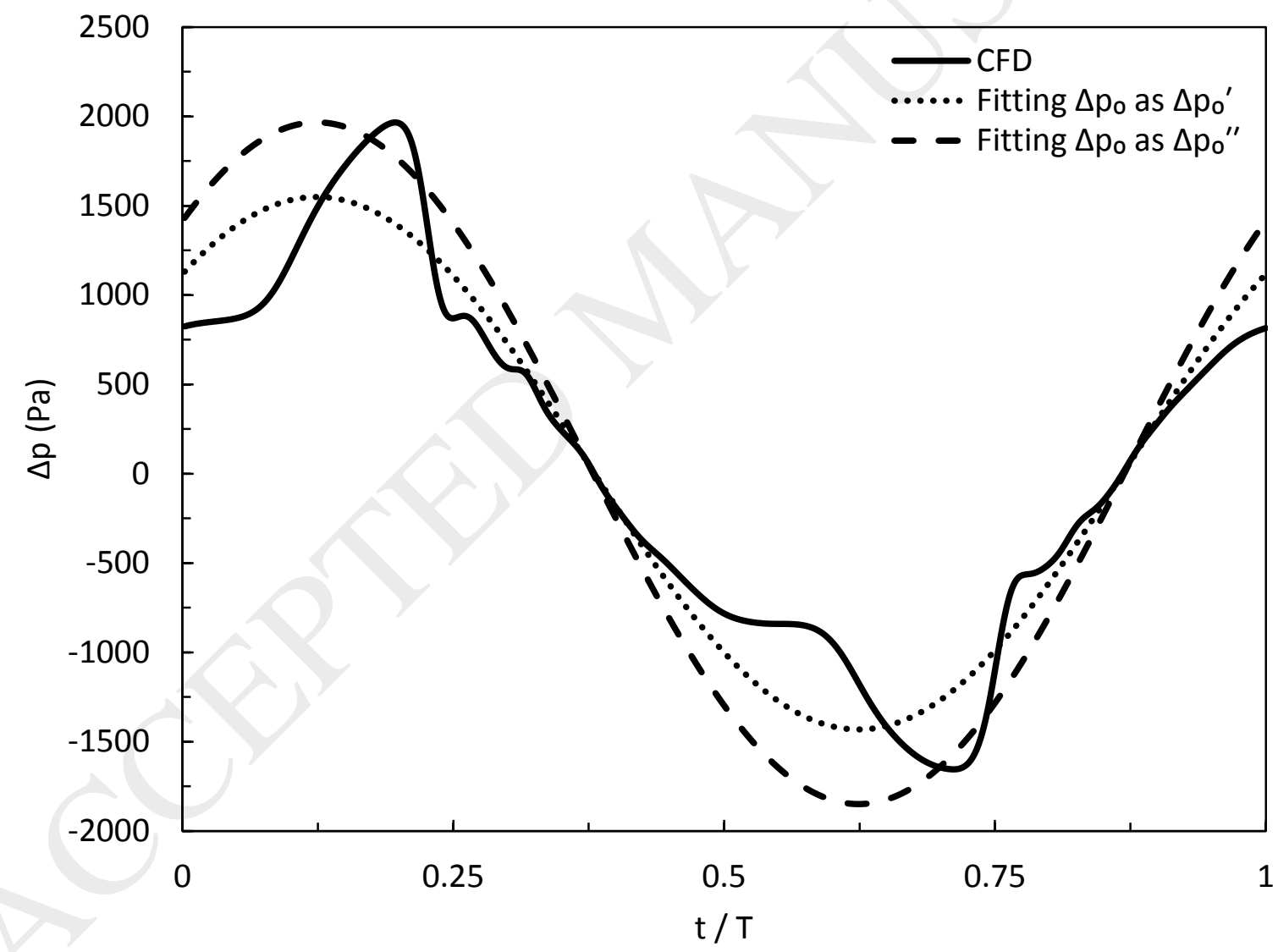

Figure 6. Cycle-averaged $\Delta p(t)$ and its hypothetical sinusoidal form, estimating $\Delta p_{o}$ as $\Delta p_{o}{ }^{\prime}$ and $\Delta p_{o}{ }^{\prime \prime}$, for run \#2 


\subsection{Validation of quasi-steady flow model (QSM)}

Following the described procedures, power density was calculated using the QSM for all conditions listed in Table 1 and compared with those predicted by CFD simulation as shown in Figure 7, where the power density is plotted against $\mathrm{Re}_{\mathrm{o}}{ }^{\mathrm{NEW}}$. It is clearly observed that power density values predicted by the QSM for every condition were consistently higher than the simulated data; reporting an averaged absolute error (AAE) of 333 and $218 \%$ for $C_{D}=0.6$ and $C_{D}=0.7$, respectively. This over-estimation is coming from two sources:

- The orifice discharge coefficient $\left(C_{D}\right)$. A value of $0.6 \leq C_{D} \leq 0.7$ has commonly been used for the QSM in previous work; ${ }^{27-33}$ this is typically true for a standard orifice made of a sharp-edged thin plate. However, DN15 have wall baffles of smoother curvature as shown in Figure 1 ; hence $C_{D}$ should have a higher value. ${ }^{55}$

- Jealous and Johnson ${ }^{27}$ modelled frictional losses as the total gain in kinetic energy due to baffle's constriction. While this is true for a single orifice, consecutive resistances (baffles) will not necessarily increment kinetic energy linearly. Jealous and Johnson also made the assumption that the effect of consecutive orifice resistances on pressure drop was linear; there was no pressure recovery because orifices were so close to one another that no calming section was available. COBRs contain orifices of smooth curvature and optimized baffle spacing, some degree of recovery would then be expected; the effect of consecutive baffles on pressure drop should thus be of a power law relationship.

We found that by re-adjusting the value of $C_{D}$ better agreement could be obtained between the power dissipation rates predicted by the QSM and that obtained from CFD simulations. However, the best fit arrives when $C_{D}=1.3$, this is neither physically or practically feasible 
as $C_{D}$ must have a value within a $0-1$ range. As a result, an exponent is added to the number-of-baffles term in the QSM, and the best fits are obtained (as shown in Figure 8) when $C_{D}=0.8$ and $n$ is replaced by $n^{0.7}$, proving an AAE of $12 \%$, as:

$$
\varepsilon_{v}=\frac{2 n^{0.7} \rho\left(\omega x_{o}\right)^{3}\left(1 / \alpha^{2}-1\right)}{3 \pi C_{D}{ }^{2}(V / A)}
$$

In summary, the existing QSM returned higher power dissipation rates due to some of the geometric parameters of its formulation not being applicable to modern oscillatory baffled devices; this can be corrected by applying a power law dependency with $n$ and an appropriate $C_{D}$ value to account for smooth-edged baffles, as show in Figure 7. In doing so, not only have the QSM been validated, but also done for a much wider application range than previously outlined. Furthermore, it can also be stated that this newly revised QSM is valid for both batch and continuous operations, as the contribution of net flow to power dissipation rates is negligible (see Table 4). 


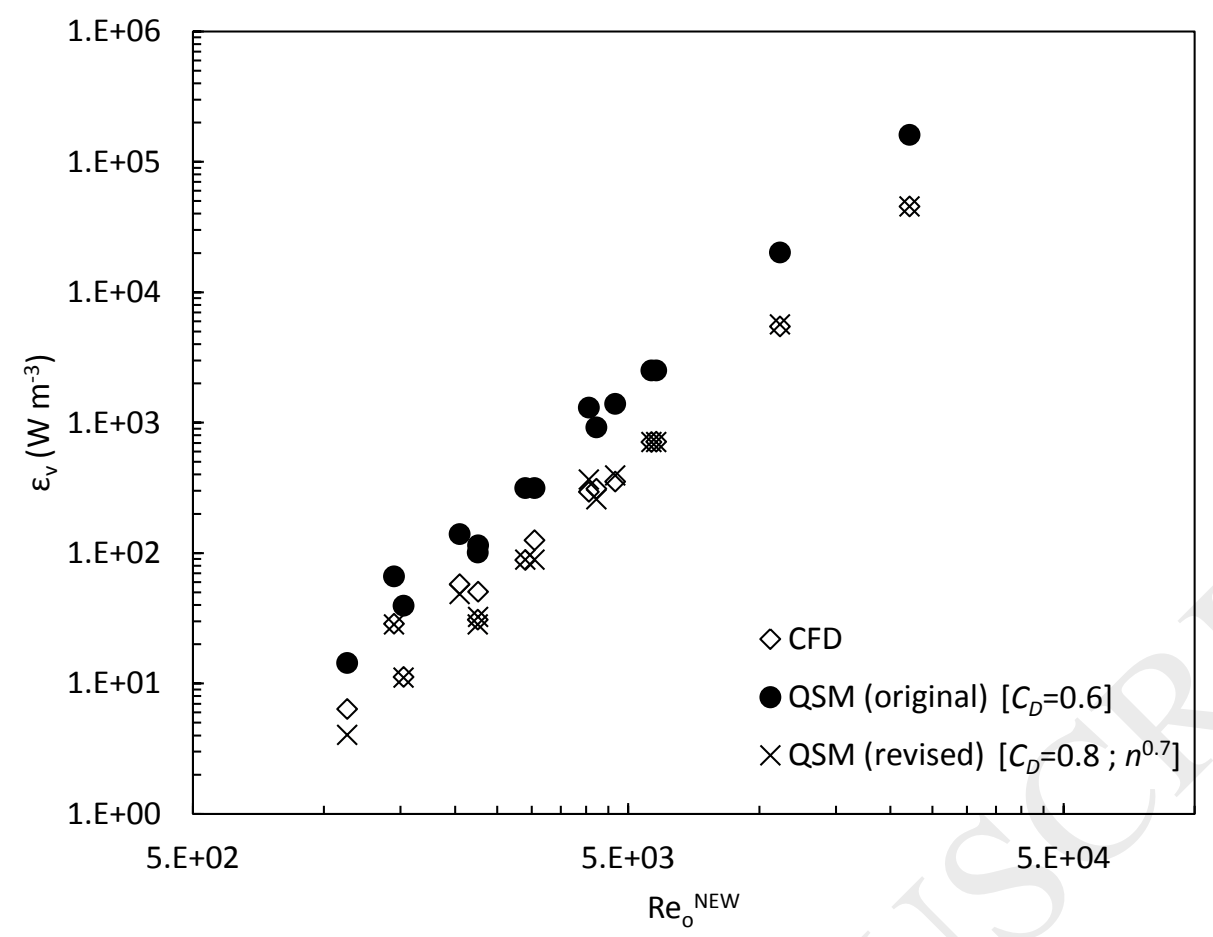

Figure 7. Simulated and QSM predicted power density as a function of $\operatorname{Re}_{o}{ }^{N E W}$ for runs \#1 to \#15 


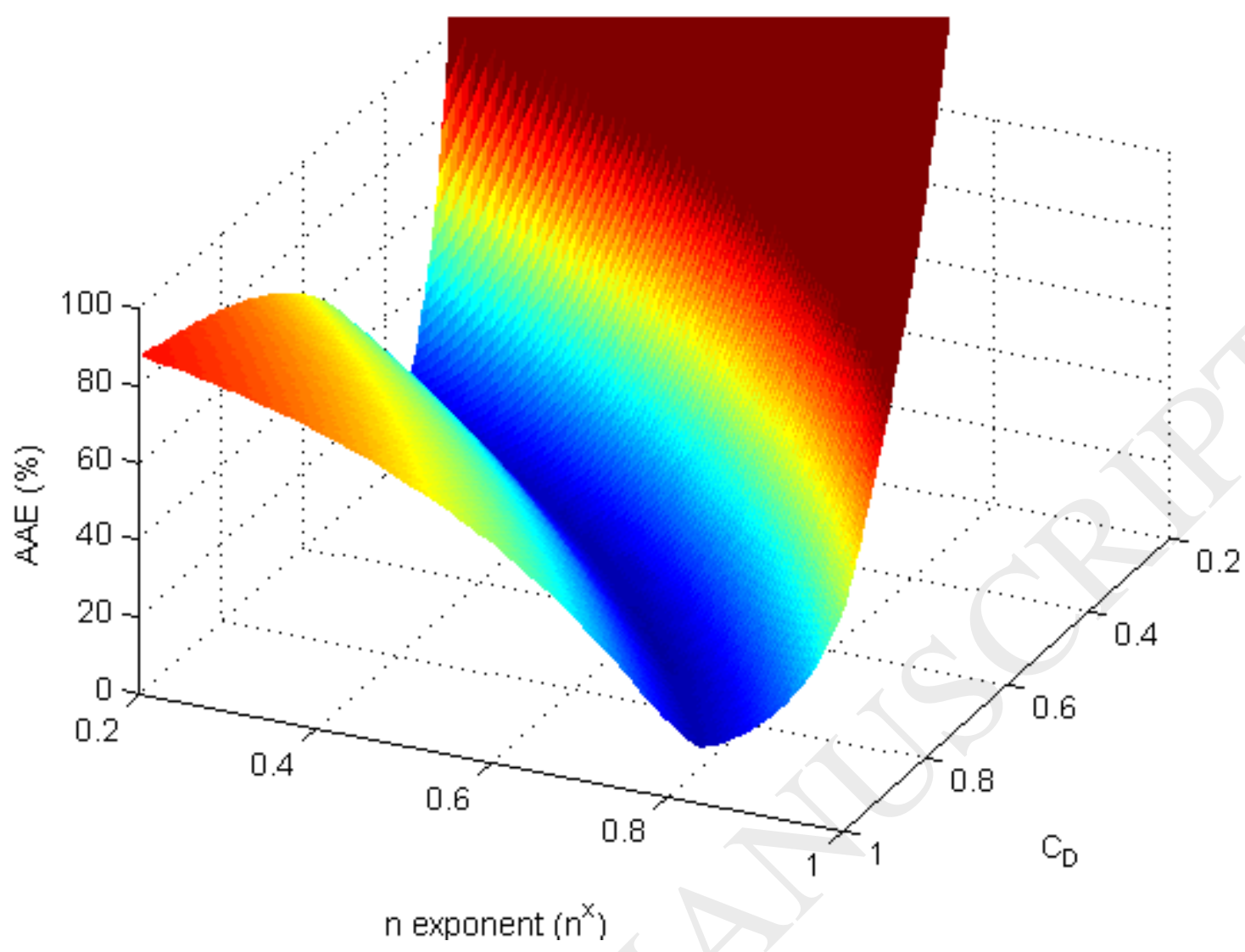

Figure 8. $A A E(\%)$ as a function of $C_{D}$ and $n$ power law exponent; minimum reached at $C_{D}=$ 0.8 and $x=0.7$

\subsection{Validation of eddy enhancement model (EEM)}

Power density from the EEM is calculated using eq. (2) taking a mixing length of $7 \mathrm{~mm}$, as suggested in previous work, ${ }^{28}$ and then compared in Figure 9 with the power density directly obtained from CFD simulations. The estimations of power density using the EEM show a better overall fit with the simulated data $(\mathrm{AAE}=58 \%)$. However, the accuracy of EEM can further be improved by implementing the same power law dependency proposed earlier $\left(n^{0.7}\right)$ to the number of baffles in the system: 
$\varepsilon_{v}=\frac{1.5 n^{0.7} \rho \omega^{3} x_{o}^{2} \ell}{\alpha(V / A)}$

reducing the averaged absolute error to $42 \%$. Additionally, the accuracy of the model can significantly be improved by properly estimating the "mixing length", which is dependent on operational and geometric characteristics. Further discussion on this very "mixing length" is taken-up in the next sub-section. Along with $\varepsilon_{v}$ values obtained from eq. (2) and those obtained from CFD simulations, Figure 9 displays power dissipation rates obtained from eq. (12), inputting estimated "mixing length" values as proposed in section 5.3.1. In summary, we have not only validated the EEM, but also done so for a much wider application range than previously outlined. Again, due to the minimal effects of net flow on power density, our validation of the EEM is applicable for both batch and continuous operations.

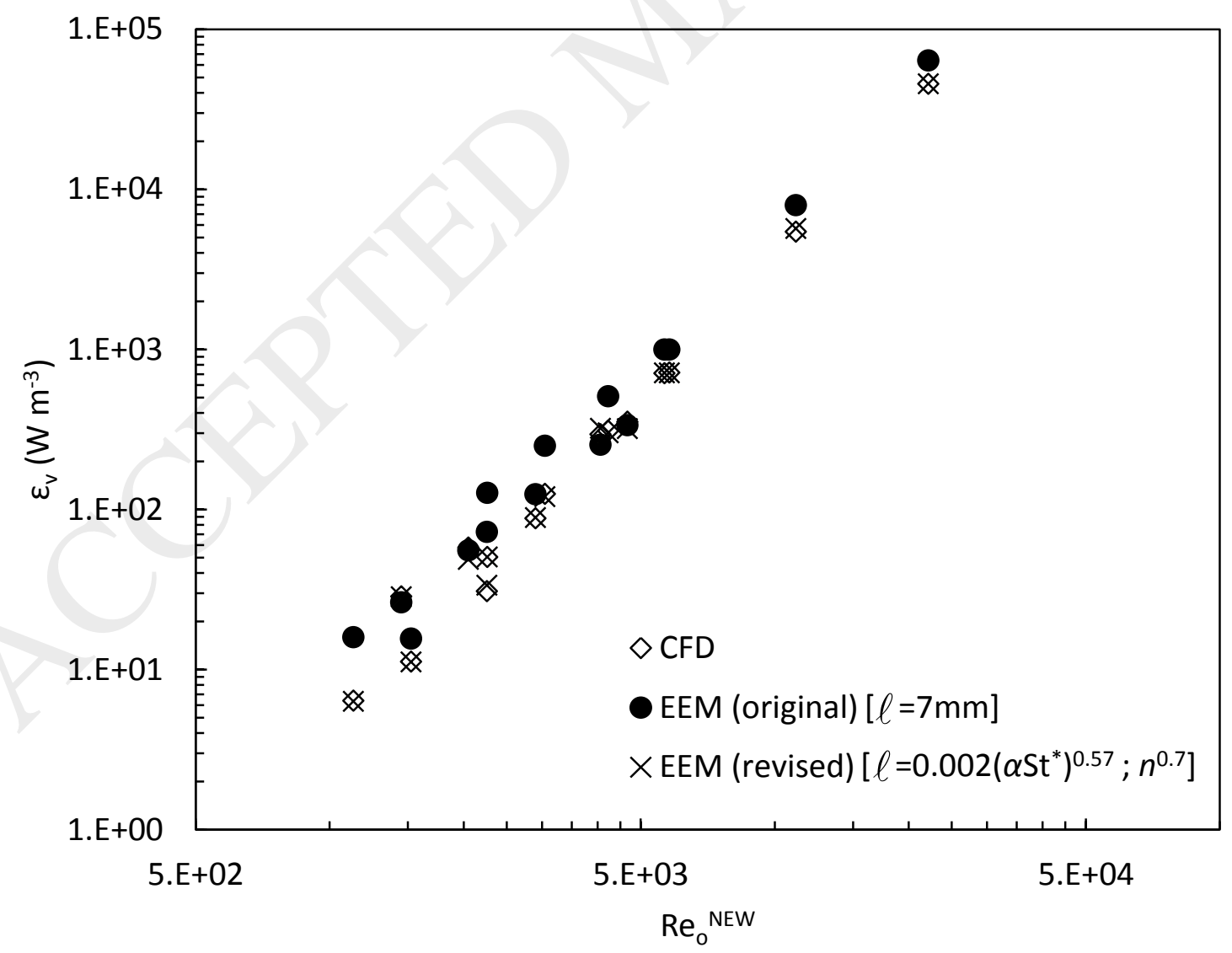


Figure 9. Simulated and EEM predicted power density as a function of $\operatorname{Re}_{o}{ }^{N E W}$ for runs \#1 to \#15

\subsubsection{Discussion on mixing length}

As aforementioned, the EEM bases the prediction of frictional pressure drop on the acoustic resistance of a single orifice plate ${ }^{28}$ as $\Delta p_{o}^{\text {friction }}=3 u \rho(v \omega)^{0.5}$, arguing that kinematic viscosity $(v)$ can be substituted by an eddy kinematic viscosity, $v_{e}=\ell^{2} \omega$, at high velocities. In this way, the "mixing length" $(\ell)$ variable was introduced in EEM; $\ell$ is however a rather loose term, as the former viscosity often refers to macro scales, while mixing length is associated with micro scale. In turbulent flows, large eddies are generated and dissipated into small ones, those further dissipate into smaller eddies and so on, i.e. energy cascading. There are generally three turbulent length scales: Kolmogorov scale, Taylor scale and integral length scale. The latter is comparable to the characteristic length scale of any given system, and sometimes referred to as the turbulent integral length scale $\left(l_{o} \propto k^{3 / 2} / \varepsilon\right)$ where $k$ is turbulent kinetic energy and $\varepsilon$ the turbulent dissipation rate of this kinetic energy. Turbulent integral length scale denotes the distance over which fluid elements are moved due to turbulent eddies; the determination of such a length scale for any reactor system is not a trivial matter, a good example of this is the work by Ni et al. where a sub-grid turbulent model was employed. ${ }^{56}$ It is unknown whether the "mixing length" in eq. (2) refers to the turbulent integral length scale; however, Baird \& Stonestreet ${ }^{28}$ referred to it as "the average distance of travel of turbulent eddies" and gave it a value of $7 \mathrm{~mm}$, which is within the same scale as the characteristic length of the system. Hence, thinking of it as the turbulent integral length scale seems appropriate. 
By equating eq. (12) to the power density obtained from simulated results using eq. (4), the "mixing length" can directly be calculated for all the simulated conditions; by doing so, the dependency of the "mixing length" on both geometric and operational parameters can be examined as shown in Figure 10. Clearly, baffle diameter and oscillation amplitude are the key parameters affecting "mixing length", while the rest have little impact. The influence of amplitude on "mixing length" discovered in our work agrees with the findings reported by Reis et al., ${ }^{57}$ in which an increment in amplitude (at constant frequency) resulted essentially in an increment in mixing length, thus increasing mixing in the axial direction and reducing it radially. Similarly, when $D_{b}$ is small, formed eddies occupy more radial space enhancing radial mixing and suspension of solids (if present), while a bigger $D_{b}$ leads eddies to occupy more axial space. The values of "mixing length" found in our work range from 7.6 to 22.1 mm, agreeing with the concept of "mixing length", which cannot be greater than $L_{b}\left(L_{b}=\right.$ $23.5 \mathrm{~mm}$ for all runs except for \#10 and 11). Baffle spacing set the maximum value mixing length could achieve for a given system, however $L_{b}$ alone does not have an impact on mixing length if the rest of operating and geometric parameters are kept constant. It is the combination of the oscillatory amplitude and the baffle orifice diameter that determines the scale of the mixing length.

A good rough estimation for "mixing length" is $\ell=x_{o}$, which reduced the AAE reported down to $18 \%$. This study concludes that the "mixing length" is not a constant for a given device and should appropriately be estimated for each individual run. Figure 11 plots the "mixing length" as a function of the dimensionless group $\alpha S t^{*}$, which captures the direct and inverse relationship of "mixing length" with $D_{b}$ and $x_{o}$ respectively, where $S t^{*}=\frac{D_{b}}{\pi x_{o}}$ is the revised Strouhal number proposed by Ni and Gough. ${ }^{50}$ Hence, an empirical correlation for the 
estimation of "mixing length" is proposed: $\ell=0.002\left(\alpha S t^{*}\right)^{-0.57}$. This correlation for the estimation of $\ell$, as opposed to a borrowed value of $7 \mathrm{~mm}$, significantly improves the accuracy of EEM, reducing the averaged absolute error from $42 \%$ to $4 \%$. 

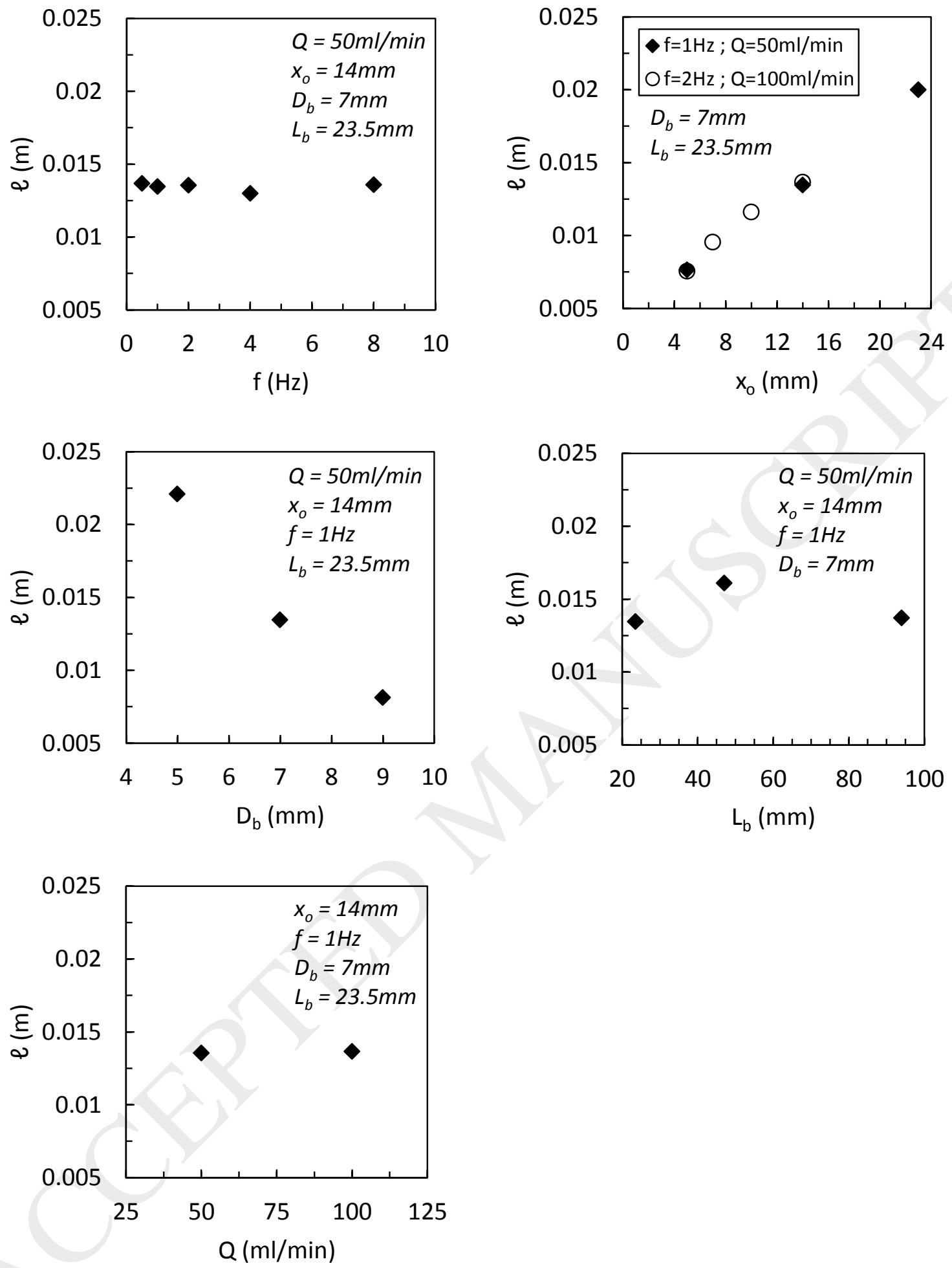

Figure 10. Mixing length change with $f, x_{o}, D_{b}, L_{b}$ and $Q$ 


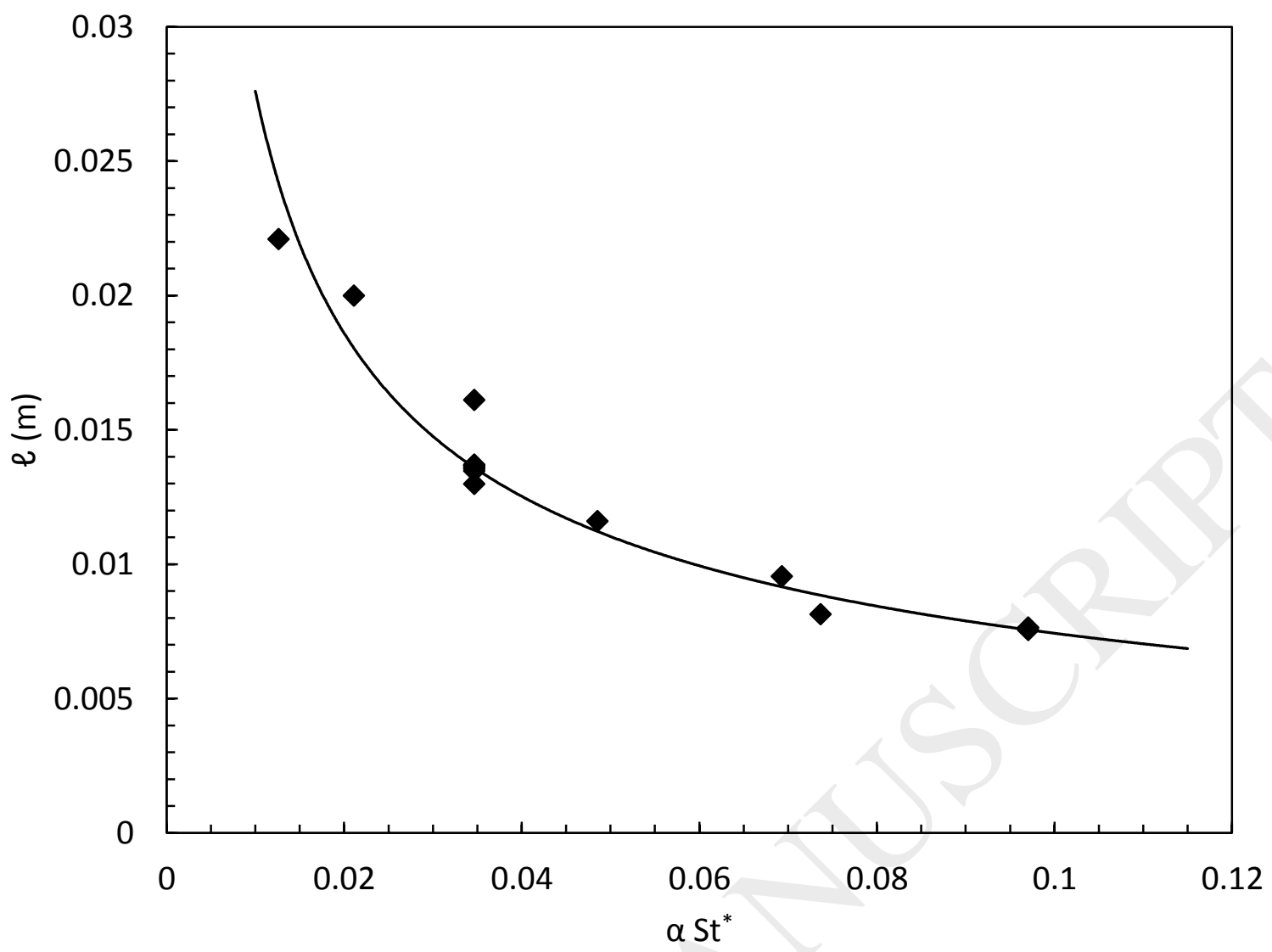

Figure 11. Mixing length as a function of $\alpha \mathrm{St}^{*}$ for runs \#1 to 15

\section{Conclusions}

In this work, we have, for the first time, provided CFD validations to the two existing models for the estimation of power density in oscillatory baffled devices. The existing QSM overestimates power dissipation rates due to the inappropriate formulation of two of its geometric parameters for modern OBRs/COBRs. By using a revised power law dependency on the number-of-baffles term $\left(n^{x}\right)$ and an appropriate $C_{D}$, the QSM was subsequently validated for a much wider application range than previously outlined. The EEM generally provides better predictions of power density for the conditions tested; however, its accuracy can substantially 
be improved by making use of the same power law dependency on $n$ and an empirical correlation of estimating EEM's "mixing length" that is proposed in this work; we have again validated the EEM for a much wider application range than originally stated. This work has also demonstrated that both the QSM and EEM are applicable for continuous operations, as net flow contribution to power dissipation rates is negligible in oscillatory baffled reactors. In addition, both revised models consistently predict similar power densities for every case, both presenting a high degree of agreement with our CFD simulations and reporting small AAE values for the wide range of geometric and operating conditions tested. This suggests that these two models can be used interchangeably with high confidence.

\section{Acknowledgements}

The authors wish to thank the EPSRC and Heriot-Watt University for the financial support provided for this project and the Doctoral Training Centre in Continuous Manufacturing and Crystallization EPSRC (EP/K503289/1). We also thank the EPSRC funded ARCHIE-WeSt High Performance Computer (EP/K000586/1).

\section{Nomenclature}
$A A E$ averaged absolute error (\%)
A reactor's cross-sectional area $\left(\mathrm{m}^{2}\right)$
$C_{D} \quad$ orifice discharge coefficient
$D \quad$ tube diameter (m)
$D_{b} \quad$ baffle hole diameter (m)
$f \quad$ oscillation frequency $(\mathrm{Hz})$
$g \quad$ gravity $\left(\mathrm{m} \mathrm{s}^{-2}\right)$
$k \quad$ turbulent kinetic energy $\left(\mathrm{m}^{2} \mathrm{~s}^{-2}\right)$ 
$K_{i} \quad$ inertial correction factor

$\ell \quad$ "mixing length" (m)

$l_{o} \quad$ turbulent integral length scale (m)

$L \quad$ reactor's length (m)

$L_{b} \quad$ spacing between baffles (m)

$L_{b}{ }^{\text {opt }} \quad$ optimum spacing between baffles (m)

$n \quad$ number of baffles

$Q \quad$ volumetric flow rate $\left(\mathrm{m}^{3} \mathrm{~min}^{-1}\right)$

$\mathrm{Re}_{\mathrm{o}} \quad$ oscillatory Reynolds number

$\mathrm{Re}_{\mathrm{n}} \quad$ net Reynolds number

$\operatorname{Re}_{0}{ }^{N E W}$ new oscillatory Reynolds number proposed in this work

St Strouhal number

$S t^{*} \quad$ oscillatory Strouhal number proposed by Ni \& Gough ${ }^{50}$

$t \quad$ time (s)

$T \quad$ oscillation period (s)

$u \quad$ velocity $\left(\mathrm{m} \mathrm{s}^{-1}\right)$

$u_{n e t} \quad$ inlet net velocity $\left(\mathrm{m} \mathrm{s}^{-1}\right)$

$V \quad$ reactor's volume $\left(\mathrm{m}^{3}\right)$

$x_{o} \quad$ oscillatory center-to-peak amplitude (m)

$\alpha \quad$ the ratio of the area of orifice over the area of tube (the restriction ratio)

$\beta \quad$ optimal to used baffle spacing ratio $\left(L_{b}{ }^{o p t} / L_{b}\right)$

$\delta \quad$ phase shift angle (rad)

$\Delta p \quad$ pressure drop $(\mathrm{Pa})$

$\Delta p_{\text {net }}$ pressure drop $(\mathrm{Pa})$ 


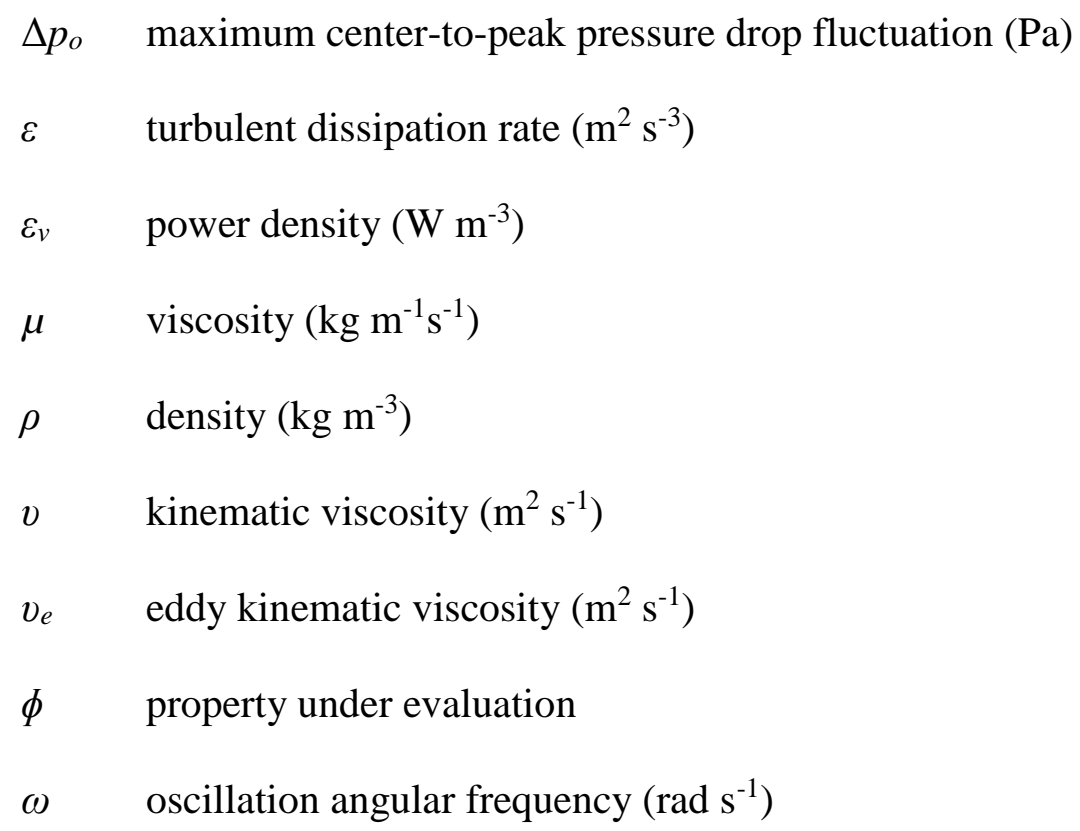

\section{References}

1. Chew CM, Ristic RI, Dennehy RD, De Yoreo JJ. Crystallization of Paracetamol under Oscillatory Flow Mixing Conditions. Crystal Growth \& Design. 2004;4(5):1045-1052.

2. Ni X, Valentine A, Liao A, Sermage SBC, Thomson GB, Roberts KJ. On the Crystal Polymorphic Forms of l-Glutamic Acid Following Temperature Programmed Crystallization in a Batch Oscillatory Baffled Crystallizer. Crystal Growth \& Design. 2004;4(6):1129-1135.

3. Chew CM, Ristic RI. Crystallization by oscillatory and conventional mixing at constant power density. AIChE Journal. 2005;51(5):15761579.

4. Ristic RI. Oscillatory Mixing for Crystallization of High Crystal Perfection Pharmaceuticals. Chemical Engineering Research and Design. 2007;85(7):937-944.

5. Ni X, Liao A. Effects of Cooling Rate and Solution Concentration on Solution Crystallization of l-Glutamic Acid in an Oscillatory Baffled Crystallizer. Crystal Growth \& Design. 2008;8(8):2875-2881.

6. Lawton S, Steele G, Shering P, Zhao L, Laird I, Ni X-W. Continuous Crystallization of Pharmaceuticals Using a Continuous Oscillatory Baffled Crystallizer. Organic Process Research \& Development. 2009;13(6):1357-1363.

7. Ricardo C, Xiongwei N. Evaluation and Establishment of a Cleaning Protocol for the Production of Vanisal Sodium and Aspirin Using a 
Continuous Oscillatory Baffled Reactor. Organic Process Research \& Development. 2009;13(6):1080-1087.

8. Ni X, Liao A. Effects of mixing, seeding, material of baffles and final temperature on solution crystallization of l-glutamic acid in an oscillatory baffled crystallizer. Chemical Engineering Journal. 2010;156(1):226-233.

9. Brown CJ, Ni X-W. Evaluation of Growth Kinetics of Antisolvent Crystallization of Paracetamol in an Oscillatory Baffled Crystallizer Utilizing Video Imaging. Crystal Growth \& Design. 2011;11(9):39944000.

10. Brown CJ, Ni X-W. Determination of metastable zone width, mean particle size and detectable number density using video imaging in an oscillatory baffled crystallizer. CrystEngComm. 2012;14(8):29442949.

11. Callahan $\mathrm{CJ}$, Ni X-W. Probing into Nucleation Mechanisms of Cooling Crystallization of Sodium Chlorate in a Stirred Tank Crystallizer and an Oscillatory Baffled Crystallizer. Crystal Growth \& Design. 2012;12(5):2525-2532.

12. Callahan CJ. PhD thesis: The influence of hydrodynamic environment on the nucleation mechanism of a chiral crystallization. Edinburgh, Scotland: Department of Chemical Engineering, Heriot-Watt University; 2014.

13. Callahan CJ, Ni X-W. An investigation into the effect of mixing on the secondary nucleation of sodium chlorate in a stirred tank and an oscillatory baffled crystallizer. CrystEngComm. 2014;16(4):690-697.

14. Briggs NEB. PhD thesis: Polymorph control of pharmaceuticals within a continuous oscillatory baffled crystalliser. Glasgow, Scotland: Institute of Pharmacy and Biomedical Sciences, University of Strathclyde; 2015.

15. Briggs NEB, Schacht U, Raval V, McGlone T, Sefcik J, Florence AJ. Seeded Crystallization of $\beta$-l-Glutamic Acid in a Continuous Oscillatory Baffled Crystallizer. Organic Process Research \& Development. 2015;19(12):1903-1911.

16. Brown CJ, Adelakun JA, Ni X-w. Characterization and modelling of antisolvent crystallization of salicylic acid in a continuous oscillatory baffled crystallizer. Chemical Engineering and Processing: Process Intensification. 2015;97:180-186.

17. Su Q, Benyahia B, Nagy ZK, Rielly CD. Mathematical Modeling, Design, and Optimization of a Multisegment Multiaddition Plug-Flow Crystallizer for Antisolvent Crystallizations. Organic Process Research \& Development. 2015;19(12):1859-1870. 
18. Ni X, Zhang Y, Mustafa I. Correction of polymer particle size with droplet size in suspension polymerisation of methylmethacrylate in a batch oscillatory baffled reactor. Chemical Engineering Science. 1999;54:841-850.

19. Phan AN, Harvey AP, Rawcliffe M. Continuous screening of basecatalysed biodiesel production using New designs of mesoscale oscillatory baffled reactors. Fuel Processing Technology. 2011;92(8):1560-1567.

20. Phan AN, Harvey AP, Eze V. Rapid Production of Biodiesel in Mesoscale Oscillatory Baffled Reactors. Chemical Engineering \& Technology. 2012;35(7):1214-1220.

21. Wilson B, Ni X, Sherrington DC. On the Investigation of a PhaseTransfer Catalysis Reaction in an Oscillatory Baffled Reactor. Industrial \& Engineering Chemistry Research. 2001;40(23):53005304.

22. Eze VC, Phan AN, Pirez C, Harvey AP, Lee AF, Wilson K. Heterogeneous catalysis in an oscillatory baffled flow reactor. Catalysis Science \& Technology. 2013;3(9):2373-2379.

23. Navarro Fuentes F, Keane MA, Ni X. A comparative evaluation of a multiphase catalytic hydrogenation in an oscillatory baffled reactor and a stirred tank reactor. Organic Process Research \& Development. 2018;Submitted.

24. Gaidhani HK, McNeil B, Ni X-W. Production of pullulan using an oscillatory baffled bioreactor. Journal of Chemical Technology \& Biotechnology. 2003;78(2-3):260-264.

25. Jambi E, Ni X, McNeil B, Basaleh A, Harvey L. Comparative study of the power consumption on the production of xanthan using the traditional industrial stirred tank reactor and a novel oscillatory baffled reactor. Life Science Journal. 2013;10(4):2241-2249.

26. McDonough JR, Phan AN, Harvey AP. Rapid process development using oscillatory baffled mesoreactors - A state-of-the-art review. Chemical Engineering Journal. 2015;265(0):110-121.

27. Jealous AC, Johnson HF. Power requirements for pulse generation in pulse columns. Industrial \& Engineering Chemistry. 1955;47(6):11591166.

28. Baird MHI, Stonestreet P. Energy dissipation in oscillatory flow within a baffled tube. Trans. IChem.E. 1995;73(A):503-511.

29. Mackley MR, Stonestreet $P$. Heat transfer and associated energy dissipation for oscillatory flow in baffled tubes. Chemical Engineering Science. 1995;50(14):2211-2224. 
30. Ni X, Gao S. Scale-up correlation for mass transfer coefficients in pulsed baffled reactors. The Chemical Engineering Journal. 1996;63(3):157-166.

31. Ni X, Brogan G, Struthers A, Bennett DC, Wilson SF. A Systematic Study of the Effect of Geometrical Parameters on Mixing Time in Oscillatory Baffled Columns. Chemical Engineering Research and Design. 1998;76(5):635-642.

32. Ni X, Cosgrove JA, Arnott AD, Greated CA, Cumming RH. On the measurement of strain rate in an oscillatory baffled column using particle image velocimetry. Chemical Engineering Science. 2000;55(16):3195-3208.

33. Stonestreet P, Harvey AP. A Mixing-Based Design Methodology for Continuous Oscillatory Flow Reactors. Chemical Engineering Research and Design. 2002;80(1):31-44.

34. Ni X, De Gélicourt YS, Baird MHI, Rao NVR. Scale-up of single phase axial dispersion coefficients in batch and continuous oscillatory baffled tubes. The Canadian Journal of Chemical Engineering. 2001;79(3):444-448.

35. Panton RL, Goldman AL. Correlation of nonlinear orifice impedance. The Journal of the Acoustical Society of America. 1976;60(6):13901396.

36. Mackley MR, Mackay M, Wang Y. Oscillatory flow within tubes containing wall or central baffles. Trans I.Chem.E. 1991;69:506-513.

37. Mazubert A, Fletcher DF, Poux M, Aubin J. Hydrodynamics and mixing in continuous oscillatory flow reactors-Part II: Characterisation methods. Chemical Engineering and Processing: Process Intensification. 2016;102:102-116.

38. González-Juárez D, Solano JP, Herrero-Martín R, Harvey AP. Residence time distribution in multiorifice baffled tubes: A numerical study. Chemical Engineering Research and Design. 2017;118:259-269.

39. Ni X, Jian H, Fitch AW. Computational fluid dynamic modelling of flow patterns in an oscillatory baffled column. Chemical Engineering Science. 2002;57(14):2849-2862.

40. Fitch AW, Jian H, Ni X. An investigation of the effect of viscosity on mixing in an oscillatory baffled column using digital particle image velocimetry and computational fluid dynamics simulation. Chemical Engineering Journal. 2005;112(1-3):197-210.

41. Reis N, Harvey AP, Mackley MR, Vicente AA, Teixeira JA. Fluid mechanics and design aspects of a novel oscillatory flow screening mesoreactor. Chemical Engineering Research and Design. 2005;83(4):357-371. 
42. Mazubert A, Fletcher DF, Poux M, Aubin J. Hydrodynamics and mixing in continuous oscillatory flow reactors-Part I: Effect of baffle geometry. Chemical Engineering and Processing: Process Intensification. 2016;108:78-92.

43. Kimuli EN, Onyemelukwe II, Benyahia B, Rielly CD. Characterisation of axial dispersion in a Meso-scale Oscillatory Baffled Crystalliser using a Numerical Approach. In: Espuña A, Graells M, Puigjaner L, eds. Computer Aided Chemical Engineering. Vol 40: Elsevier; 2017:223-228.

44. González-Juárez D, Herrero-Martín R, Solano JP. Enhanced heat transfer and power dissipation in oscillatory-flow tubes with circular-orifice baffles: a numerical study. Applied Thermal Engineering. 2018;141:494-502.

45. Jian $\mathrm{H}, \mathrm{Ni} \mathrm{X}$. A numerical study on the scale-up behaviour in oscillatory baffled columns. Chemical Engineering Research and Design. 2005;83(10):1163-1170.

46. Manninen $\mathrm{M}$, Gorshkova $\mathrm{E}$, Immonen $\mathrm{K}, \mathrm{Ni} \mathrm{X}-\mathrm{W}$. Evaluation of axial dispersion and mixing performance in oscillatory baffled reactors using CFD. Journal of Chemical Technology \& Biotechnology. 2013;88(4):553-562.

47. Ekambara K, Dhotre MT. Simulation of oscillatory baffled column: CFD and population balance. Chemical Engineering Science. 2007;62(24):7205-7213.

48. Hamzah AA, Hasan N, Takriff MS, et al. Effect of oscillation amplitude on velocity distributions in an oscillatory baffled column (OBC). Chemical Engineering Research and Design. 2012;90(8):1038-1044.

49. Jian H. PhD thesis: Understanding unsteadiness and turbulence in two chemical engineering systems. Edinburgh, Scotland: Department of Chemical Engineering, Heriot-Watt University; 2002.

50. Ni X, Gough P. On the discussion of the dimensionless groups governing oscillatory flow in a baffled tube. Chemical Engineering Science. 1997;52(18):3209-3212.

51. Brunold CR, Hunns JCB, Mackley MR, Thompson JW. Experimental observations on flow patterns and energy losses for oscillatory flow in ducts containing sharp edges. Chemical Engineering Science. 1989;44(5):1227-1244.

52. Fitch AW, Ni X, Stewart J. Characterisation of flexible baffles in an oscillatory baffled column. Journal of Chemical Technology \& Biotechnology. 2001;76(10):1074-1079.

53. Zheng M, Li J, Mackley MR, Tao J. The development of asymmetry for oscillatory flow within a tube containing sharp edge periodic baffles. Physics of Fluids. 2007;19(11):114101. 
54. Phan AN, Harvey A. Development and evaluation of novel designs of continuous mesoscale oscillatory baffled reactors. Chemical Engineering Journal. 2010;159(1-3):212-219.

55. W. Miller R. Flow Measurement Engineering Handbook. Third ed: McGraw-Hill Education; 1996.

56. Ni X, Jian H, Fitch A. Evaluation of Turbulent Integral Length Scale in an Oscillatory Baffled Column Using Large Eddy Simulation and Digital Particle Image Velocimetry. Chemical Engineering Research and Design. 2003;81(8):842-853.

57. Reis N, Vicente AA, Teixeira JA, Mackley MR. Residence times and mixing of a novel continuous oscillatory flow screening reactor. Chemical Engineering Science. 2004;59(22-23):4967-4974. 